\title{
Novel \& worthy: creativity as a thick epistemic concept
}

\section{Julia Sánchez-Dorado ${ }^{1}$}

Received: 28 November 2019 / Accepted: 5 August 2020 / Published online: 17 September 2020

(C) The Author(s) 2020

\begin{abstract}
The standard view in current philosophy of creativity says that being creative has two requirements: being novel and being valuable (to which a third intentionality requirement is often added; Sternberg and Lubart 1999; Boden 2004; Gaut 2010). The standard view on creativity has recently become an object of critical scrutiny. Hills and Bird (2018) have specifically proposed to remove the value requirement from the definition, as it is not clear that creative objects are necessarily valuable or creative people necessarily praiseworthy. In this paper, I argue against Hills and Bird (2018), since eliminating the element of value from the explanation of creativity hinders the understanding of the role that creative products play in actual epistemic practices, which are fundamentally normative. More specifically, I argue that the terms 'creativity' and 'creative' function as thick epistemic concepts when employed by competent epistemic agents in practice, that is, these concepts have both a descriptive and an evaluative content that cannot be disentangled from one another. Accordingly, I suggest that philosophers should prefer thick accounts over thin accounts of creativity. A thick account of creativity is one that endorses the standard view at its basis, but further develops it in two ways: by stressing the entanglement of the value and novelty requirements; by permitting to encompass a range of domain-specific characterizations of such entanglement for different epistemic situations. In order to take the first steps in the development of such a thick account of creativity, I look at the domain of scientific practices as a case in point, and try to spell out what the thickness (or entanglement of novelty and worth) of creative instances typically entails here. Namely, I identify the worthy novelty of creative models and methods with their potential to clarify a tradition, with fruitfulness, and with the fulfilment of exploratory aims.
\end{abstract}

This article belongs to the Topical Collection: Creativity in Art, Science \& Mind Guest Editors: Adrian Currie, Anton Killin

Julia Sánchez-Dorado

juliasanchezdorado@gmail.com

1 Max Planck Institute for the History of Science, Berlin, Germany 
Keywords Creativity $\cdot$ Thick concepts $\cdot$ Epistemic values $\cdot$ Novelty $\cdot$ Exploration ·

Fruitfulness

\section{Introduction}

One of the most widely adopted definitions of creativity in contemporary philosophical debates says that creativity is the ability to produce novel and valuable objects (Boden 2004: 1; Sternberg and Lubart 1999), to which an element of intentionality or agency is often added (Kieran 2014; Stokes 2008; Gaut 2012). Also known as the standard view on creativity, this definition appears to capture what is crucial about creativity when we employ the concept in everyday talk. From moments when we praise a child for producing a whimsical drawing, to encounters with artworks that astound us, and to occasions when we celebrate a new scientific invention, we refer to certain objects and ideas that are both novel and valuable as creative. Moreover, the way in which creativity is treated by governing, regulatory, and educational organizations reinforces the idea that creative products are highly valuable. The United Nations "regards creativity as a major component not only of spiritual life, but also of the material and economic life of persons and populations". 1 The European Commission has developed the programme Creative Europe to provide "conditions for innovation and creativity $[\ldots]$ that can be turned into products and services that create growth and jobs and help address societal changes" (European Commission. Regulation (EU) No 1295/2013). The BIAC of the OECD sustains that creativity is "essential for sustainable growth and economic development" (BIAC - OECD 2003). A similar praise for creativity seems to be ingrained in our accounts of the past. General histories of science and art describe how the greatest individuals of each domain exemplify extraordinary creativity. Einstein, Picasso, da Vinci and Mozart are considered to possess the "gift of creative genius" (Miller 1998), in virtue of which they produced exceptionally novel and valuable works that brought progress to the societies in which they lived. We could say that the idea of the genius has for very long served as the paradigm of what being creative is about.

Looking at these common assumptions, it is not surprising that we quickly associate creativity with something highly treasured. However, the unconditional appraisal of creativity has recently become an object of critical scrutiny. When so many accomplishments and merits are associated to creativity, we might need to reconsider what we are exactly praising when we praise it, and recalibrate the scope of the achievements that creativity can actually comprise. Some philosophers of art and science have for instance rejected the idea of the creative genius altogether, as it only consolidates a romantic myth around certain individuals who are supposed to possess an innate gift and experience moments of inspiration that cannot be rationally explained. This myth, they argue, hampers the project of naturalizing creativity or studying it also as part of ordinary cognitive processes in everyday practices (see Kronfeldner 2014; Gaut 2012;

\footnotetext{
${ }^{1}$ In 2017 the UNESCO resolved to establish a Creativity Day to "raise awareness of the role of creativity and innovation in problem-solving and, by extension, economic, social and sustainable development" (UNESCO 2017).
} 
Carroll 2010; and Weisberg 1986 for arguments against the myth of the creative genius). ${ }^{2}$ Another criticism to the standard view on creativity has been recently formulated by Alison Hills and Alexander Bird (2018) with regards to the value requirement in it. These philosophers argue that we should refrain from assuming that being valuable is necessary for being creative. In their article "Against Creativity", Hills and Bird reject "the unreflective approval of creativity", which is "both widespread and deeply misguided", and propose a new explanation of the phenomenon of creativity in which the element of value is absent except for very exceptional circumstances (Hills and Bird 2018: 18).

In this paper, I examine the specific arguments that Hills and Bird (2018) offer to reject the standard view, and conclude that they are not persuasive enough to convince us to remove the value requirement from the definition of creativity. With a focus on epistemic contexts, I show that we should keep the element of value in any fruitful explanation of creativity because, as a matter of fact, the terms 'creativity' and 'creative' function as thick epistemic concepts in practice (Williams 1985; Dancy 1995; Putnam 2002; Kirchin 2013). That is to say, these concepts, when employed by competent epistemic agents to qualify certain objects (ideas, acts, etc.), express both an evaluative attitude towards such objects (identifiable with an element of epistemic worth) and a descriptive attitude (identifiable with an element of novelty), which cannot be disentangled from one another. In other words, creativity attributions assign a "novel worth" or "worthy novelty" to the objects they qualify. Accordingly, I argue that philosophers should prefer thick accounts over thin accounts of creativity. Drawing on recent proposals to advance thicker forms of epistemology (Axtell and Carter 2008; Elgin 2008; Roberts 2018; Poznic 2018), I define a thick account of creativity as one that endorses the standard view at its basis, but further develops it in two ways: by stressing the entanglement of the value and novelty requirements; by permitting to encompass a range of domain-specific, narrowed-down, and flexible characterizations of such entanglement for different epistemic situations.

Crucially, the arguments I present here are compatible with a critical attitude towards the myth of the creative genius, the unreflective approval of creative ideas and objects, and the misattribution of unwarranted merits to creative people. That is, this paper does not aim to extol the value of creativity in general but to spell out the restricted sense in which creative instances can be epistemically worthy in concrete situations. For instance, I believe that we should refrain from identifying the epistemic value of creativity in general with the value of thin concepts, which are predominant in traditional epistemology, such as 'justification', 'knowledge' or 'true belief' (Axtell and Carter 2008; Kotzee and Wanderer 2008; Roberts 2018). Creativity, like other thick epistemic concepts, entails a sui generis form of value, attached to a novelty aspect, that needs to be characterized in its own terms. Taking scientific practices as a case in point, I try to spell out what the sui generis value of creativity usually comprises in this domain. In science, I observe, the novel worth of creative models and methods can be typically identified with the clarification of a tradition, fruitfulness, and the fulfilment of exploratory aims.

\footnotetext{
${ }^{2}$ Also numerous historians of science and art have rejected the ideal of the creative genius for different but complementary reasons, that is, this ideal overemphasizes individual achievement against the context of the time and work of others (see Fara 2002; Schaffer 1994). I thank the editors of this topical collection for their input on this, among many other, points throughout the paper.
} 
I start section 2 disputing Hills and Bird's (2018) arguments in favour of a value-free definition of creativity, while acknowledging some important criticisms to the standard view they make. Then, in section 3, I propose to understand creativity as a thick epistemic concept, based on how epistemic agents actually make creativity attributions. Lastly, in section 4, I focus on scientific practices, and suggest some ways of spelling out what the epistemic worth of creative models and methods usually comprises. These final suggestions should be taken as a first step towards the advancement of a more comprehensive thick account of creativity in the future, which would also include an analysis of the value of creative instances in other epistemic contexts, as well as aesthetic and everyday contexts.

\section{Creativity without value: Response to Hills and Bird (2018)}

The standard view on creativity can be traced back to Kant in the Critique of Judgment, where he defines the creative genius as someone who produces works that are "original" and at the same time "exemplary" (1790/2001: 43-50). In recent philosophy of creativity, the standard view has been endorsed among others by Sternberg and Lubart (1999: 3), who argue that creativity is "the ability to produce work that is both novel (i.e., original, unexpected) and appropriate (i.e., useful, adaptive concerning task constraints)", and Boden (2004: 1), who argues that it is "an ability to come up with ideas or artefacts that are new, surprising and valuable". Other philosophers in the debate usually accept the standard view as an adequate, although minimal, explanation of creativity, and propose to expand it adding other conditions. Kieran (2014), Gaut (2012), and Stokes (2008) for instance argue that the definition of creativity requires to include some form of intentionality in order to avoid cases of accidental creativity. For Kieran (2014) what is required is "motivation", for Gaut (2012) "flair", and for Stokes (2008) "agency". There are, in addition, ongoing debates about whether the definition of creativity should be principally focused on creative individuals -in which case creativity is understood as a disposition or ability- or on creative objects, creative processes, or even creative groups (Currie 2018; Stokes and Paul 2016; Klausen 2010; Paulus and Coskun 2011).

At the risk of losing scope of these various interrelated debates in the current philosophy of creativity, I would like to focus on one particular attempt to invalidate the standard view by philosophers Hills and Bird (2018). In their article "Against Creativity", they propose a substantial redefinition of the concept of creativity with respect to the standard view, which consists in eliminating the value requirement, keeping the novelty requirement, and adding three further requirements, namely imagination, fertility, and motivation (Ibid.: 7). Although this section mainly focuses on contesting the first of these moves, I will introduce some brief considerations to how Hills and Bird's proposed role for the imagination can enrich an account of creativity understood as a disposition of individuals.

Hills and Bird ask themselves the questions: are creative works always valuable?, are creative people unquestionably praiseworthy?, and respond negatively to them. For that reason, they claim, it is necessary to reject the unreflective approval of creativity, and only acknowledge the connection between being creative and being valuable in very unusual circumstances in which the right conditions are met (Hills and Bird 2018: $2,18)$. Three specific reasons are offered to support this position: 1) it is possible for 
creative people to manifest their creativity -one and the same disposition-in producing good ideas and bad ideas; 2) it is possible to know that an object has been produced creatively without knowing its value; and 3) creativity can produce objects of wholly negative value (Ibid.: 8). In the following, I argue that none of these specific reasons is sufficiently convincing.

\subsection{Creative people can produce good and bad ideas}

The first argument that Hills and Bird offer to eliminate the value requirement from the definition of creativity is introduced with the help of the following example:

William Herschel discovered the planet Uranus and also infrared radiation; yet he also had entirely false ideas about other planets (that the Moon was rather like the English countryside, that the surface of the Sun was cool and inhabited). It is simply not plausible that one set of dispositions (creativity) produced the good ideas of [...] Herschel and quite another generated the bad ones. Distinguishing between their good and bad ideas in term of creativity is neither psychologically realistic nor explanatorily appropriate nor descriptively useful. (Hills and Bird 2018:12)

If being valuable is necessary for being creative, so the argument goes, one would have to postulate that Herschel's creativity was responsible for the discovery of Uranus and infrared radiation, while another disposition was responsible for the false, worthless claims that Herschel made. This is highly counterintuitive though. We would usually assume that it was the same set of dispositions that allowed Herschel to produce objects of value sometimes, and valueless objects other times. Thus, Hills and Bird argue, we should explain creativity in terms of novelty and the use of the imagination (also motivation and fertility), without introducing a value requirement, so that we can account for the possibility of being creative and nevertheless producing bad ideas.

This argument focuses on creativity as a disposition of individuals. It rightly assumes that not all the ideas produced by an individual, even a historically exemplary scientist like Herschel, were true or good. Indeed, most people would easily accept that scientists and artists have unfortunate ideas sometimes, and this includes philosophers who endorse the standard view on creativity as well. This fact, however, does not present any serious challenge for their endorsement of the standard view, contrary to what Hills and Bird imply. I believe that it is possible to contest argument 1) after examining what Hills and Bird mean with producing "good" and "bad" ideas in the quote above. There, they appear to identify a good idea with a true idea and a bad idea with a false idea (Hills and Bird 2018: 12). Thus, they separate Herschel's ideas into two groups, one for ideas that are true and therefore valuable, and one for ideas that are false and therefore worthless. ${ }^{3}$ This is, however, a way of understanding the value requirement in the definition of creativity that we don't have to endorse.

Indeed, in everyday talk, as well as in specialized epistemic and aesthetic practices, we rarely attribute value to a creative idea in the sense of considering it, qua creative, "valuable as true", "valuable as good in general" or "value as good tout court". If we

\footnotetext{
${ }_{3}^{3}$ In section 2.2. I refer back to Hills and Bird's (2018) views on true and false ideas and discuss them more precisely.
} 
think that a good idea can only be valuable in any of these three ways, then I agree with Hills and Bird that "distinguishing between good and bad ideas in term of creativity is [...not] explanatorily appropriate" (Hills and Bird 2018: 12). What I am suggesting is that an account of creativity does not have to define the value of creativity in any of these ways, because, as a matter of fact, our attributions of value to creative objects and people are much more limited and specific in practice. An account of creativity should, instead, characterize creative products as "valuable-in-a-way" in relation to their novelty, and always dependent on the aims and standards of acceptability of certain community. As Gaut (2018: 141) has also argued, creative products are never "valuable simpliciter" or "valuable period", but valuable in a conditional manner that depends on the kinds and contexts to which those products belong.

Thus, a standard view advocate could accept that some ideas are both bad and creative, if with bad one understands that they are neither valuable in general nor substantially true. Yet, a standard view advocate would sustain that they are valuablein-a-way that relates to the role of their novelty. To put it in other words, one could unproblematically claim that Herschel's ideas about Uranus as much as his ideas about the surface of the Moon were creative, and qua creative they were valuable-in-a-way. But this does not imply that one ought to consider all of Herschel's ideas equally valuable. We may think that his ideas about Uranus were more valuable than his ideas about the surface of the Moon, but just because they were, apart from creative, also more predictively accurate, externally consistent, and observationally rigorous. In section 4, I offer a more specific characterization of what "valuable-in-a-way" usually comprises for the case of creative models and methods in scientific practice.

\subsection{We can recognize creative objects without knowing their value}

The second argument that Hills and Bird (2018) offer to defend a value-free definition of creativity asks the question: "Do we need to know the value of what has been produced in order to know whether it has been produced creatively?". To it, they respond negatively as well (Ibid.: 11). The example that Hills and Bird introduce this time are Leonardo da Vinci's famous sketches of flying machines. They claim that "we do not need to know whether Leonardo's designs stood any chance of working nor whether if they did they would have been of use to anyone in order to judge that these ideas manifested his creativity" (Ibid.: 12). Although I agree with this claim, it is for different reasons than the ones that Hills and Bird have. While I do not think that there has to be a final working object actually constructed to be able to judge whether da Vinci's sketches were valuable or not, Hills and Bird fundamentally associate the value of da Vinci's sketches with their truth or realizability. For that reason, they claim to be judging da Vinci's sketches creative "without knowing their value" (Ibid.). On the contrary, I sustain that when we judge da Vinci's sketches creative we are already ascribing them -and probably the process that gave rise to them- a (limited) value connected to their novelty, whether or not such value translates into a workable device or a set of substantially true statements afterwards. 
More specifically, da Vinci's sketches are valuable (qua creative) because they informed and expanded a previous tradition of studies on flight and air resistance. As Galluzi (2020: 103-106) has argued, his designs advanced "bold analogies" between the flight of birds and man-powered mechanisms, and served as instruments for visualizing theoretical hypotheses regarding the problem of human aviation. Even if most of da Vinci's theoretical hypotheses on flight were never successfully realized, the sketches advanced understanding of the differences between the power-to-weight ratio in birds and in humans (Kemp 2006: 104-106, 249-250). For instance, they helped to see that the quest for aviation could not be based on the imitation of the full dynamism of natural flight, as the power-to-weight ratio in humans proved this unfeasible, but it could be based, at least partially, on the mechanical imitation of birds' gliding motions in air currents (Ibid.). In fact, Kemp (2006: 249-250) observes that some of da Vinci's wing designs proved to function well in hang-glidering.

Arguably, the hang-glidering case is an exception and for most of da Vinci's sketches there is no evidence of objects constructed after them that demonstrate the truth of his hypotheses. Still, the sketches should be considered epistemically valuable qua creative because they condense a variety of technical, mathematical, and pictorial resources in a way that expands a tradition in the study of human flight and air resistence. Importantly, the fact that the value of creativity in cases like this is not translatable into realizability or truth does not mean accepting "original nonsenses" as possible cases of creativity (see Kant 1790/2001: 43-50, and based on it Gaut 2010: 1039, and Paul and Kauffman 2014 for arguments regarding the idea of "original nonsense"). This is because nonsense is not valuable in any epistemically relevant way, while creative products are valuable-in-a-way. And da Vinci's sketches are far from being nonsense: they are intelligible and build on previous studies of animal and mechanical flight.

At some point Hills and Bird (2018) certainly remark that their conception of value is not exclusively identifiable with truth: "of course we acknowledge that a scientific theory may not be true (even approximately) but may nevertheless have some kind of value, contributing in some degree to the progress of science" (Ibid.: 9). They mention "knowledge, understanding, or anything else of scientific value" as possible alternatives to truth in defining the value of creativity (Ibid.: 14). This might appear to locate Hills and Bird's position closer to the idea of "valuable-in-a-way" that I am endorsing here. However, their acknowledgment of epistemic value beyond truth is still very constrained and cannot accommodate the type of characterizations of epistemic worth that I am contemplating here (see sections 3 and 4). This is because, one, Hills and Bird appear to hold a strongly factive conception of what "knowledge, understanding, or anything else of scientific value" are, which is patent in their assessment of the epistemic achievements of Herschel or Ancient Greek science, among other examples they use, exclusively in terms of the true claims they produced (Ibid.). Two, the most explicit way in which Hills and Bird recognize epistemic value beyond truth is by claiming that "discovering why the theory is false may increase our grasp of the subject matter" (Ibid.: 9). This is, however, a very narrow way of conceding epistemic merit to scientific theories that are not (literally or substantially) true. It doesn't say anything about the qualities of such theories or how we might learn from them, but only that 
recognizing their falsity may help us advance in our inquiry by eliminating them. In contrast, I propose to endorse a flexible conception of epistemic value, as spelt out below, that is able to recognize the worth of creative instances also when they involve rough approximations, useful metaphors, or strong idealizations that are not substantially true (Elgin 2008, 2017; Potochnik 2015, 2017). ${ }^{4}$

\subsection{Creativity can produce objects of wholly negative value}

Lastly, argument 3) is, I believe, the strongest reason Hills and Bird (2018) offer to support a value-free definition of creativity. They argue that creative people can produce objects of wholly negative value, as it is shown in cases of 'malevolent' or 'dark creativity' (Gaut 2010: 1039; also see Cropley et al. 2008; Cropley 2011; Novitz 2003; McLaren 1993). These cases are situations that we recognize as creative, but that concern matters such as committing a crime, murdering, producing torture instruments, or carrying out reprovable actions of other kinds. Cropley (2011) and James and Taylor (2010) have for instance discussed the attacks of 9/11 as a notorious recent case of dark creativity. The example that Hills and Bird introduce is the following:

The zealot of the French Revolution, Jean-Baptiste Carrier, executed his victims in increasingly novel and imaginative ways, including the infamous "Republican Marriage" whereby a male prisoner and a female prisoner would be bound together, naked, and then thrown into the Loire. Creativity can be put to work in doing bad and wrong acts, just as in doing good. [...] So creativity cannot be a disposition to produce objects that have objective value. (Hills and Bird 2018: 8)

Despite our revulsion to Carrier's method of execution, we would usually acknowledge that he was creative at devising and performing his crimes. Since deplorable actions like this have an openly negative value, to include a (positive) value requirement in the definition of creativity -so the argument goes- has to be a mistaken. However, I believe that it is possible to address the challenge of dark creativity appealing to the idea of "valuable-in-a-way" introduced above.

It would be helpful to start by comparing the term 'creative' with others such as 'intelligent', 'precise', 'rigorous', 'thoughtful', 'elegant'. We typically employ these concepts as epistemic or aesthetic values, and sometimes as intellectual virtues too. In philosophy of science for instance, 'precision', 'elegance' and 'rigour' are discussed as important epistemic values for theory choice or model construction (Kuhn 1977; Anderson 2004; Douglas 2013). In aesthetics and art criticism, an artwork that is thought-provoking would be judged 'intelligent' or 'thoughtful', and artists are praised for their 'elegance' or 'precision (see also Turner 2019 and Breitenbach 2020 on the use of aesthetic judgments in scientific practice). Yet, all these terms can have a dark side as

\footnotetext{
${ }^{4}$ Here I am endorsing the view, defended among others by Elgin (2017) and Potochnik $(2015,2017)$, that the production of true beliefs is not the most important epistemological endeavour in the domain of science, but, instead, it is the advancement of (non-necessarily-factive) understanding. Defending this particular view is beyond the scope of this article. At any rate, my aim here is to propose a flexible characterization of the value of creativity, for which we do not necessarily need to endorse such particular view, but only acknowledge that in common epistemic practices -such as those discussed in section 4-competent epistemic agents recognize the worth of creative products in terms that are not reducible to (or exclusively identifiable with) truth.
} 
well. It is possible to say that "a criminal has been 'rigorous' and 'thoughtful' in the way he executed his crimes", that "the murdering was 'precise' and 'intelligent", and that a "certain method of execution was "elegant". The question is whether situations of dark creativity (as well as 'dark elegance', 'dark thoughtfulness', 'dark rigour', etc.) are significant enough to convince us to stop identifying these concepts with values and virtues, and, instead, treat them as valueless or evaluatively neutral concepts to which we might exceptionally attach a positive or a negative valence. I believe that it would be unfortunate, at least from the perspective of a philosophical analysis that is wellgrounded in epistemic practices, to do so and take these concepts out of our common stock of values and virtues, given how prevalent and useful they are in such practices to make evaluations about the adequacy of certain objects, ideas, or processes. So, even if we admit that cases of dark creativity are a challenge for the standard view on creativity, we might lose more explanatory power redefining creativity as a valueless concept -as the key to understanding its typical role is its functioning as a positive value or a virtue- than we would gain from accounting for these exceptional dark cases.

In any case, I do not believe that cases of dark creativity are really a challenge for the standard view on creativity. When we admit that a despicable crime was creative, we are, very much to our regret, noting that the crime was novel, and that such novelty has a merit at least in the sense that it allows us to see more clearly a tradition of a certain type of crime, understand patterns in it, and possibly also suggest new effective ways of achieving (despicable) goals. This does not mean that we have to approve the consequences of the criminal acts, nor need we to feel moral esteem for the criminals. But we are conceding some kind of credit to the ability of certain individuals to come up with novel ways of effectively carrying out planned actions in comparison to how they were carried out in the past. In fact, it is difficult to imagine that we would judge crimes that we know were totally ineffective or didn't trigger any consideration to how previous crimes were committed as cases of dark creativity. ${ }^{5}$ Evidence that we are expressing an element of worth when we assign an immoral act the adjective 'creative' is that doing so provokes us discomfort, uneasiness, and that we would usually say that we have to "admit" or "concede" that it was creative. If creativity was a value-free or evaluatively neutral concept, the uneasiness would be unjustified.

At any rate, Hills and Bird (2018: 8) could reply that if the previous argument was right, then calling evil acts creative would "mitigate the harm produced so we can say that the torture was horrific, but at least it was produced creatively". Contrary to this, "if anything, that very fact makes things worse" (Ibid.). I agree with Hills and Bird that this might be frequently the case. The reason, though, is not that the concept of creativity is value-free and that it can indistinctly carry a negative or a positive valence. Calling evil acts creative might make them worse because it outrages us that people's disposition for creativity, their efforts, abilities, and motivations, are put to the service of morally contemptible goals. But this fact is independent from recognizing that judging some evil acts creative is attributing them a value-in-a-way, that is, a merit that involves a

\footnotetext{
$\overline{5}$ Following a suggestion of a reviewer, one might wonder about the existence of creative crimes that we don't hear or know about that could have been ineffective. This paper is interested in how epistemic agents actually attribute the concept 'creative' to certain objects, ideas, and people in their practices. The aim is not to establish an objective measure of creativity that allows us to say whether something that we don't know about is creative or not, including cases of dark creativity. So unknown and unheard cases of crimes (or anything else we don't have access to) are not relevant for the debate here.
} 
type of novelty, which typically allows us to better understand similar preceding acts. Ultimately, there is a plurality of values, epistemic and non-epistemic, usually in tradeoff with one another. And creativity is only one among them, as I discuss in section 4. So even if we attribute a (very specific, restricted) epistemic value to evil acts when we admit that they are creative, we can be attributing them at the same time multiple and stronger negative values of an epistemic, moral, and social kind.

Note that my response to argument 3) is different from other recent ways of addressing the challenge of dark creativity. Novitz (2003: 78) for instance tries to respond to the challenge arguing that cases of dark creativity are not genuine cases of creativity, but cases of "ingenious destruction". Cropley (2011: 353) argues that cases of dark creativity such as the 9/11 attacks are valuable only in the sense that for a small group of people (i.e. the hijackers), they were noble, useful, and morally commendable acts. And Gaut (2018: 129) argues that creative products are only valuable of their kind, and that some kinds may be bad ones (e.g. terrorist acts, torture devices). Although these arguments help elucidate different aspects of the problem of dark creativity, I believe that they fail to fully capture our intuitions about cases of dark creativity such as the attacks of 9/11. Many of us have the impression that the attacks of 9/11 were indeed creative, not just "ingeniously destructive", as Novitz (2003) argues, while we feel uneasy recognizing it, that is, while not sharing the views of the perpetrators, which is the explanation that Cropley (2011) offers. Moreover, this uneasiness becomes stronger when we realize that by recognizing the creativity of the 9/11 attacks we are ascribing them a merit that might go beyond the very specific kind 'terrorist acts' to which they belong, as Gaut (2018) argues. That is, our attribution of creativity (and therefore of value-in-a-way) to these acts might involve a broader acknowledgement of merit that reaches kinds concerning the use of strategies, tactical skills, or organizational abilities (even if it would not reach kinds directly involving moral goods or fairness). ${ }^{6} \mathrm{My}$ response to argument 3) can do a better job at capturing these various intuitions, by basically not denying that there is a limited ascription of value when we call certain instances creative, including cases of dark creativity.

I contended that arguments 1), 2), and 3) are not persuasive enough to convince us to discard the standard view on creativity and endorse a value-free definition thereof. Yet, it is important to acknowledge that Hills and Bird (2018) have contributed to the recent debate about the value of creativity in several ways. First, they have brought to the fore the fact that many valuable things in science and art are not the product of creativity, and that more creativity is not necessarily better (Ibid.: 17-18). An account of creativity should certainly accommodate this fact, and highlight, as I try to do in section 4 for the case of scientific practices, that things can be epistemically valuable for many different reasons, being their creativity just one among them. Second, Hills and Bird have rightly criticized the vagueness or ambiguity with which the value requirement is often formulated in definitions of creativity. They note that "defenders of the standard view are not always completely clear about the kind of value they have in mind when they say that creativity is a disposition to produce value" (Ibid.: 8). Indeed, this lack of

\footnotetext{
${ }^{6}$ In any case, disagreeing with Gaut (2018) for locating objects in kinds that are too narrow in order to respond to the challenge of dark creativity is compatible with accepting his general claim that the value of creativity ought to be understood in relation to certain contexts, domains, and historical circumstances, as I further defend in sections 3 and 4 .
} 
clarity has given rise to the misattributions of unwarranted merits to creative ideas and people and, I believe, also motivated philosophers like Hills and Bird themselves to reject the standard view as it stands. My suggestion, as it will become clearer in the next sections, is that we should, instead of rejecting the standard view, address this lack of clarity by further advancing a range of characterizations of the value of creativity for different epistemic situations. Third, Hills and Bird have offered a rich reconceptualization of creativity as largely a matter of the imagination, which I believe can significantly contribute to our explanations of the phenomenon of creativity when understood as a disposition of individuals (perhaps not so directly to explain creativity as a quality of objects or processes) (Ibid.: 2, 18). ${ }^{7}$ Thus, I suggest that, in future works, Hills and Bird's proposal is read not necessarily in opposition to the standard view but in complementarity to it, in a way that studying the role of the imagination informs our understanding of the distinctive type of value involved in subjects' creativity attributions (see also Gaut 2003).

For now, in section 3, I offer more specific reasons for why it is important to keep a value requirement in the definition of creativity, drawing on the idea that creativity is a thick epistemic concept.

\section{Thick epistemic concepts and creativity}

A term expresses a thick concept if it expresses a specific evaluative concept that is also substantially descriptive (Kyle 2013, 2016). Bernard Williams (1985) first introduced the idea of thick concept in metaethics with his book Ethics and the Limits of Philosophy. In his own terms, a thick concept is both "world-guided" (as it picks out particular properties of the world) and "action-guiding" (as it offers reasons for action or attaches an evaluative flag to the concept) (Williams 1985: 140-1). Paradigmatic examples of thick concepts are 'courage', 'dogmatic', and 'cruel', while typical thin or purely evaluative concepts are 'good', 'bad', 'wrong', and 'right'. In recent epistemology, there is an increasing interest in discussing whether there are thick epistemic concepts as well, mirroring the debate in metaethics. ${ }^{8}$ I believe that looking precisely at these debates on thick concepts in epistemology can inform ongoing discussions in the philosophy of creativity, especially regarding the value of creativity.

\subsection{Thick concepts in epistemology}

'Creative' and 'creativity' are not purely descriptive concepts in the way 'blue' or 'water' are. They are not purely evaluative concepts either. Observing common uses of these concepts in everyday talk and, more crucially, in specialized epistemic contexts

\footnotetext{
${ }^{7}$ Hills and Bird (2018: 3) define the imagination as the "ability to produce a particular type of mental representation", and attribute it two specific uses in creativity: one, to help "find ways of simultaneously meeting a number of constraints", such as when a poet tries to find the right poetic form and, at the same time, the right words to express an emotion; and two, to "bring together ideas perhaps from what were, until now, different [...] traditions" (Ibid.: 17).

${ }^{8}$ A point of controversy here is whether the epistemic is sufficiently like the ethical to conclude that the same distinction between thin and thick holds for the epistemic domain. Roberts (2018) presents strong arguments to defend that they are, and I am assuming the same here.
} 
such as scientific practices, should make us recognise them as thick epistemic concepts. ${ }^{9}$ Traditionally in epistemology, the concepts that have occupied central stage are thin concepts, that is, those that function in a fundamentally evaluative or normative way, such as 'justification', 'warrant', and 'knowledge'. However, a growing group of epistemologists contend that thick epistemic concepts might actually be more prevalent than thin concepts in practice. Thus, paying more attention to them would help revivify current philosophical analysis (Kotzee and Wanderer 2008: 342; see also Putnam 2002; Axtell and Carter 2008; Roberts 2018). Paradigmatic examples of thick epistemic concepts include 'curious', 'intellectual humility', 'open-mindedness', and 'dogmatic'. And other recent attempts to identify thick epistemic concepts can be found in Elgin (2008), who discusses 'trustworthiness'; Siegel (2008), who discusses 'education'; Poznic (2018), who discusses 'scientific representation'; and Alexandrova (2017), who discusses 'well-being'. 10

Let us take 'dogmatic' as an illustrative example of a term that expresses a thick concept. When we say that "Maria is dogmatic" we are doing two things: describing her as holding strong beliefs, and evaluating her negatively for doing so (Kyle 2016). We could indeed think of situations where holding strong beliefs is not seen in a negative way, for instance when someone has willingness to discuss her beliefs rationally. But this would not be a reason to deny that 'dogmatic' is a thick term that entails a negative evaluative stance. In those situations, we just wouldn't use the term dogmatic. Instead, we would say that Maria is assertive or faithful to her beliefs. Similarly, if we thought that da Vinci's sketches were completely worthless, we wouldn't call them creative, in the same way we don't call my doodling in the margin of the page creative. When epistemic agents decide to attribute da Vinci's drawings the adjective 'creative' - if they do so- they are expressing an evaluation in the form of a (limited) attribution of merit, even if this merit does not translate into value in general, value tout court, or truth.

Also, one could conceive of situations where the use of the term 'dogmatic' could change. For instance, in a historical context where the instability of beliefs in a community is pervasive, the term dogmatic might start to be adopted to praise individuals who are able to commit to their beliefs. Perhaps these conceivable situations are a challenge for someone who wants to establish an undisputable, fixed definition of the term 'dogmatic'. Whether it is possible to achieve that or not is a semantic point that I will not address here. But what seems certain is that, if the goal is to advance an informative characterization of the phenomenon of dogmatism as we experience it, it is not a good strategy to start by treating the term 'dogmatic' as if it did not function as a thick concept that expresses a negative evaluation on how certain beliefs are held. In other words, it is doubtful that a value-free definition of dogmatism would help us

\footnotetext{
${ }^{9}$ I also believe that creativity is a thick aesthetic concept, and many of the things I argue in what follows help support this idea too. Other examples of thick aesthetic concepts are 'gracefulness', 'dumpiness' or 'elegance', (see Williams 1985: 140-145; Kirchin 2013; Zangwill 2001; Bronzon 2009; Kyle 2016). However, I will only discuss thick epistemic concepts in this paper, since the debate on thick aesthetic concepts deals with peculiar difficulties that require separate analysis. I also avoid here the problem of how the realms of the aesthetic, the epistemic, and the ethical overlap to an important extent.

${ }^{10}$ More precisely, Alexandrova (2017: 83-4) discusses 'well-being' not as an example of "thick concept" but of "mixed claim". She proposes the expression "mixed claims" in part to avoid the foundational controversies attached to the debate on thick concepts, although acknowledging the closeness between these terminologies.
} 
understand our actual experiences with dogmatic ideas and dogmatic people. In a similar vein, if we propose a value-free definition of creativity, we would be overlooking the evaluative content that is most characteristic of our ascriptions of the term to certain people and objects, thus hindering our grasp of the phenomenon they conceptualize.

A clarification is required here. The discussion about thick concepts might seem so far to be a problem of conceptual analysis, that is, a problem of how to analyse the words 'creative' and 'creativity' and not about what creativity is. This is not exactly so. Following Elgin (2008: 372), a terminological discussion might be helpful to begin with, but the goal of discussing the particularities of thick terms is not to produce a dictionary with exact definitions, but to elucidate "the constitution of the epistemic realm", which elements comprise it and how they relate to each other. Traditionally, there were two different things we could do with language: evaluate and describe (Roberts 2018: 162). If thick concepts can do the two things at the same time, and we conclude that concepts like 'curiosity', 'trustworthiness' and 'creativity' are thick and play important roles in our epistemic practices, we would have to reassess how our epistemic realm is constituted according to this.

\subsection{Entanglement}

A fundamental feature of thick concepts (both ethical and epistemic) is the tied connection between their descriptive and evaluative components (Roberts 2013; Kotzee and Wanderer 2008). The disentangling argument was formulated by McDowell (1998) precisely to expose the difficulties of separating these components, and stress the irreducible thickness of thick concepts. That is, we should not be thinking of thick concepts as having an original descriptive content, to which an evaluative stance (such as those expressed by thin concepts) is just added to it (Poznic 2018: 3435). ${ }^{11}$ The implication this has for the debate of creativity is that the evaluative component of the concept of creativity (what I identified so far as the "value requirement") cannot be understood as detached or disconnected from its descriptive component (roughly identifiable with the "novelty requirement"). Recognizing the creativity of Herschel's ideas about Uranus or about the surface of the Moon is assigning them a value attached to the novelty that such ideas exhibited. The value is not an extra aspect, but is built into the meaning of the term 'creative' when attributed to Herschel's ideas.

To see the difference between a definition of creativity that takes it as an (irreducibly) thick concept and one that allows a factor analysis of its components, it is helpful to consider Elgin's (2008: 372) newly coined predicate 'gred'. 'Gred' applies to all and only things that are good and red, so it is both a descriptive and an evaluative concept. A gred mitten, for instance, satisfies the descriptive requirement (by being red) and the evaluative requirement (by being good at warming my hand). However, "a gred

\footnotetext{
${ }^{11}$ There are actually different views on this point in the debate about thick concepts. For some philosophers it is possible to grasp what thick concepts mean even if we analytically separate their descriptive and evaluative components, because these components are connected only in a pragmatic way (Väyrynen 2013). Meanwhile, for other philosophers, especially non-reductivists, thick concepts conceptually entail evaluative content, so it is not possible to grasp their meaning separating the evaluative and descriptive components (Williams 1985; Dancy 1995; Roberts 2018; see Roberts 2013: 677-8). My proposal is closer to the latter group, but any of these positions can help sustain the arguments on the thickness of the concept of creativity presented here.
} 
item's being red has no bearing on its being good; nor has its being good any bearing on its being red. It is simply a contraction" (Ibid.). Thick epistemic concepts are not mere contractions, because without them we wouldn't be able to partition the world as we do now, marking out extensions - such as the extension of creative objects- that the mere sum of thin epistemic concepts (like good) and purely descriptive ones (like red) wouldn't be able to mark out (Ibid.: 375). We could say that thick concepts express a sui generis evaluation, that is, an evaluation that picks out particular features of the world, and is not replaceable by the sum of a thin concept and a description (Williams 1985; Kyle 2016). Advocates of thicker forms of epistemology contend that the sui generis evaluation of concepts like 'trustworthiness' and 'creative' might actually be prior and more fundamental than the evaluation expressed by thin concepts like 'knowledge', in the sense that we need the former concepts to grasp "what makes knowledge worth having" in the first place (Elgin 2008: 387; see also Kotzee and Wanderer 2008: 342; Roberts 2018: 164; Fricker 2007).

There is an additional reason to think that the evaluative and descriptive components of creativity are entangled. Namely, attempts to explain the supposedly mere descriptive part of creativity (i.e. its aspect of novelty ${ }^{12}$ ) cannot help but introduce positive value judgments. For instance, Kronfeldner (2014) argues that she "shall concentrate on novelty" in her analysis of creativity, without dealing with the issue of value (Kronfeldner 2014: 578). But then, in order to clarify in what sense something must be novel in order to be creative, Kronfeldner refers to 'originality' and 'spontaneity', understood as adequate degrees of independence from a tradition and previous learning (Ibid.: 584). This characterization suggests a positive stance on the kind of 'newness' that creativity is about. Actually, the more evaluatively neutral term to be used here would have been 'newness', but it is rarely employed to define creativity, probably given its evaluative unspecificity. When we describe something new as 'novel' and 'original', we already attribute some type of worth to it. We are saying that such newness is neither a conventional one -like a product that is new but predictable or repetitive- nor a negative one -like a product that is new but unorthodox in an undesirable or irrelevant way. In fact, 'novelty' and 'originality' could be considered thick concepts as well, with a positive evaluative flag attached to them. ${ }^{13}$

Another example of the filtration of positive value judgments in the characterization of the descriptive content of creativity can be found in Kieran (2014). Kieran discusses motivation, ${ }^{14}$ one of the requirements for creativity in his view, which is in principle separate from the value requirement. But then, he defines motivation as an "acting out of a desire to realize what makes something valuable [...], expressive, imaginative, or beautiful" (Ibid.: 129), and considers the motivation of a creative person "itself a

\footnotetext{
$\overline{12}$ Also its aspects of imagination and motivation would be part of this descriptive content of creativity, in case we develop an expanded version of the standard view focused on creativity as a disposition of individuals (see Hills and Bird 2018, Kieran 2014, and Gaut 2012).

${ }^{13}$ For the case of 'spontaneity', which Kronfeldner (2014: 588-9) also introduces to describe the kind of newness that creativity is about, I concede that this might not be a thick concept but a descriptive one. Still, philosophers like Gaut (2018) take spontaneity as encompassing an element of positive value too: "Since we value spontaneity, and creativity involves an element of spontaneity, part of the explanation for the final value of creativity lies in its dimension of spontaneity" (Ibid.: 140-1).

${ }^{14}$ More specifically, Kieran (2014) discusses "internal or intrinsic motivation". He also considers "external motivations", such as commercial gain or celebrity status, but attributes only to internal motivations the role of making creativity a virtue of character.
} 
praiseworthy achievement of character" (Ibid.: 132). So in Kieran's (2014) account, creative agents direct their motivation towards the production of epistemically or aesthetically commendable objects. Here, the value of creativity is not only present in its corresponding requirement (of value), but is strongly ingrained in the descriptive content of creativity, specifically in the motivation requirement.

In accordance with the arguments above, I suggest that philosophers should openly recognize the irreducible thickness of the concept of creativity, and advance thick accounts, instead of thin accounts, thereof. ${ }^{15}$ A thick account is one that builds on the same intuitions which underlie the standard view, as it recognizes at its basis both an element of novelty and an element of value. But it develops and refines the standard view because it stresses the entanglement between these two elements, and tries to spell out what such entanglement comprises for real epistemic situations. Meanwhile, a thin account of creativity would be one that only acknowledges the descriptive content of the concept (i.e. Hills and Bird 2018), or acknowledges both but examines them separately (Kronfeldner 2014; Kieran 2014). I believe that this latter group of thin accounts would have benefited from taking a thick turn and acknowledging the entanglement between the two contents of creativity instead of factorizing them. For instance, Kronfeldner (2014) could have advanced further insight on why originality and spontaneity are the adequate kinds of novelty that creativity requires, by referring to the ascribed value that we, as competent epistemic agents, concede to certain forms of newness (namely, those that expand our tradition and permit progress) and not to others. And Kieran (2014) could have further vindicated the importance of internal motivations by bringing in the role played by evaluative attitudes and shared value judgments in guiding subjects' creative work.

Developing a thick account of creativity requires to adopt a flexible and a domain-specific conception of epistemic value. A flexible characterization of epistemic value is one that may recognize the importance of generating new justifications or true beliefs, but also contemplates a plurality of other ways in which things can be epistemically worthy without being substantially true, or in addition to being true (Elgin 2017; Potochnik 2017). This idea is in line with numerous accounts in recent philosophy of science that highlight the existence of a plurality of values in trade-off with one another in practice, as I spell out in section 4 (Douglas 2013; Parker 2010; Anderson 2004; Kuhn 1977). Apart from flexible, the characterization of the epistemic value of creativity should be domain-specific or narrowed-down to particular situations. This is because a "mere value condition" in the definition of creativity is just uninformative (Stokes and Paul 2016: 3n). A thick account should aim to bring clarity to how actual creative instances come to be "valuable-in-a-way" in different contexts. In the next section, I take the first step towards the advancement of

\footnotetext{
15 The idea of a thick account of creativity builds on Poznic (2018), who distinguishes between thick and thin accounts of 'scientific representation'; Currie (2018), who argues that we need thick descriptions of epistemic situations, precisely in the context of discussing the role of creativity in scientific practices; and Alexandrova (2017), who highlights the importance of "mixed claims" in scientific practice, that is, claims that incorporate both an empirical hypothesis and a value judgment.
} 
a -hopefully in the future more comprehensive- thick account of creativity, focusing on scientific practices as a case in point.

\section{Creativity and the plurality of values in science}

I have thus far argued that creativity, as a thick epistemic concept, includes value in its content. But how should we capture this value, entangled with an element of novelty, in actual epistemic contexts? The aim of this section is to characterize, by narrowing down, such entanglement in a paradigmatic epistemic domain, namely scientific practices. $^{16}$

\subsection{Worth of creativity in science}

Without aiming to exhaust the task of spelling out the value of creativity for any possible situation in scientific practices, I offer three characterizations of how creative models and methods are typically epistemically valuable (qua creative). Namely, I identify the epistemic value of creative instances in science with their ability to clarify a tradition, with fruitfulness, and with the fulfilment of exploratory aims.

Drawing on Carroll (2010), one could claim that there is a minimal sense in which creative instances are valuable, and then stronger ways in which they might be so as well. The minimal sense concerns the capacity of such instances to clarify the tradition in which they are embedded (Ibid.: 70-71). Although Carroll (2010) was mainly trying to describe the value of creativity in the arts, I take this to be also a minimal, common denominator of epistemic value shared by creative instances in science. In this minimal sense, a creative scientific model, theory, or method would be epistemically worthy insofar as it shows us "the tradition and its possibilities more clearly, expansively, and perspicuously than earlier works" (Ibid.). This is because creative objects "recombined elements and concerns of the tradition in an especially deft, original, or insightful way", making our previous commitments manifest in a way that was not so patent before (Ibid.). It might be the case that some creative models and methods end up being impractical or inadequate for the scientific community that produced them, and eventually abandoned. Still, qua creative, they are epistemically valuable at least in the sense that their novelty brought some commitments of the tradition to the fore, allowing qualified epistemic agents to better discuss, understand, revise, and challenge such tradition. This, in turn, frequently increases the possibilities of an inquiry to correct itself and move forward.

A good example of a creative scientific model whose epistemic value can be spelt out in terms of the clarification of a tradition is the MONIAC or Phillip's hydraulic machine from 1949 (Vines 2000; Morgan 2012; Frigg and Nguyen 2017). Phillip's machine is a model consisting of a system of tanks, valves and pipes through which water flows, and that aimed at representing the dynamics of market demands in an

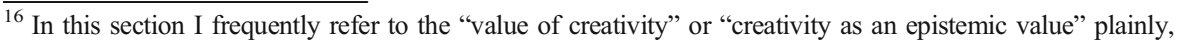
without explicitly reiterating each time that such value is a value-in-a-way attached to an element of novelty. After the arguments presented earlier, it should be clear at this point that referring to the value of creativity is equivalent here to referring to the "novel worth", "worthy novelty", "value-in-a-way", "thickness", or "sui generis evaluation" of creativity.
} 
economy. In a stagnant moment of inquiry, in which resources to reason about policy intervention on an economy seemed insufficient to make the field move forward, producing a creative model like this was particularly desirable (Vines 2000). The MONIAC exposed important commitments and resources used to represent economic systems in the past, making them now "immensely visible" (Ibid.: 58). It allowed scientists to reason about money transactions "vividly" for the first time, while looking at water tanks rise, and to ask questions about policy interventions in a very tangible manner, while operating valves and pumps manually (Ibid.: 46-49). A creative model like Phillip's machine was epistemically worthy (qua creative) to the extent that its novelty helped to expose traditional assumptions in economics suggestively, stimulating questions about how to better exploit representational resources in the field in future practices.

Indeed, the creative character of Phillips' machine did not mean that the model was prolific or successful in a stronger sense. The MONIAC did not impose a new form of modelling the dynamics of market demands in the field, as hydraulic models (or physical analogical models more broadly) would continue to be very scarce in economic research afterwards. In some cases though, allowing to clarify a tradition of past theories, methods, and representational resources with creative models proves to be highly fruitful, the key to make a whole field emerge or evolve. Fruitfulness is therefore a way of spelling out the value of creativity in scientific contexts that sometimes complements the minimal sense (see Kuhn 1977; McMullin 1976, 1979; Nolan 1999; and Ivani 2019 for discussions on fruitfulness in science; and Šešelja and Straßer 2013; and Nyrup 2018 for discussions on pursuitworthiness). If we look at other cases, such as R. A. Fisher's work in population genetics in the 1930 s, we would say that it was creative -and qua creative epistemically valuable- both in the sense that its novelty allowed to clarify a tradition, and that such clarification was highly fruitful (see Fisher 1930). Fisher's work made manifest the latent explanatory possibilities of the previously proposed Darwinian theory of natural selection and Mendelian inheritance principles, which he combined using novel mathematical models. This allowed to eventually open a whole new field of investigation that would be key in twentieth century biology, namely modern synthesis. Here the revision of the tradition not only offered a better understanding of it, but was "bountiful - its consequences have been both copious and beneficial for the practice to which it belongs" (Carroll 2010: 70).

Of course being bountiful or fruitful can only be calculated retrospectively, after having observed the branching lines of development that a certain work motivated (Carroll 2010: 70; see also Schaffer 1994). But, before we can observe that, creativity can function as an important epistemic value that helps regulate ongoing scientific practices, together with other values (epistemic and non-epistemic) that it might be in combination or trade-off with. When scientists judge that in their current work a certain model is creative, they are recognizing that the model brings to the fore some assumptions of the tradition, allowing to see patterns of it, and perhaps also that such model is appropriate for carrying out certain epistemic tasks. Exploration, I argue, is the most obvious of these tasks.

Exploratory modelling and exploratory experimentation are important parts of the scientific enterprise. They aim at getting a grasp of natural phenomena in the absence of a well-established theory, and in occasions in the absence of even a well-delineated target system (Gelfert 2018: 222-224; see also Steinle 1997, Burian 1997, Elliott 2007, 
and McLeod and Nersessian 2013 on exploratory experimentation; and Boden 2004 on "exploratory creativity"). Philosophers of science have generally paid more attention to scientific models that have explanatory or predictive potential, and only occasionally analysed the particularities of exploratory models (Gelfert 2018: 230). This has stressed the importance of epistemic values such as observational accuracy, precision, and external consistency in their analyses. Meanwhile, in exploratory research, creativity gets to be a particularly appreciated epistemic value.

A recent example in exploratory astronomical science illustrates how the value of creativity can be spelt out in the terms just described. In April 2019 the first image of a supermassive black hole situated at the centre of the M87 galaxy was publicly released. ${ }^{17}$ The achievement resulted from the work of the Event Horizon Telescope (EHT), an international team that developed a creative methodology consisting in the synchronization of large amounts of data collected at eight ground-based telescopes located at different points of the Earth. Allegedly, when all those data were synchronized, with the help of atomic clocks, complex imaging algorithms, and after filling in numerous gaps of information, a planet-sized telescope, able to produce an image of a black hole, was virtually created. This method, which comprises the coordinated use of different telescopes, can be considered highly creative -and as such epistemically valuableinsofar as it is bringing clarity to the tradition of observational and imaging methods in astronomy, by allowing scientists to see previously unseen possibilities about how to study distant astronomical objects with telescopes that have a limited resolution capacity. Moreover, the EHT, in virtue of its creative character, is proving to be especially suitable to carry out exploratory tasks: it is helping to delineate more sharply targets that are still largely unknown like black holes, and it is suggesting new possible ways of testing Einstein's theoretical claims about black holes. We are still unable to say whether this method will be prolific in the coming years. But we can certainly agree that it is a creative method that issues a promissory note about its latent fruitfulness (Carroll 2010: 71).

\subsection{Plurality of epistemic values in science}

In an attempt to offer a narrowed-down and flexible characterization of the epistemic value of creativity in scientific practice, I associated such value with its potential to clarify a tradition, frequently suggesting fruitful ways of improving it, and sometimes also helping to fulfil exploratory aims. However, there is a plurality of other epistemic values at play in scientific practices (Brown 2013; Douglas 2013; Potochnik 2015; Parker 2020). So it might be the case that a creative model is not the most desirable type of model in certain epistemic circumstances, and that a creative methodology is not the most appropriate methodology with regard to certain goals. Instead, scientists might want to prioritize values like precision, external consistency, observational accuracy,

\footnotetext{
${ }^{17}$ Press Release of the Event Horizon Telescope (on April 10, 2019): Astronomers Capture First Image of a Black Hole. https://eventhorizontelescope.org/press-release-april-10-2019-astronomers-capture-first-imageblack-hole. For full articles with results, telescope methodology, and imaging process descriptions, see: The Event Horizon Telescope Collaboration et al. (2019).
} 
scope, simplicity, or a combined balance of some of these when the circumstances demand so. On this point, I certainly agree with Hills and Bird (2018: 14) that "if creativity is in part responsible for the success of modern science, that is only because it is being used in a particular context", and not in contexts where it is not mostly required. For instance, if the purpose of a certain practice is to produce a copy or duplicate of an original (e.g. an experiment), creativity might not be necessary at all, or not in a substantial way (Ibid.: 15).

Recognizing creativity as an epistemic value (with a descriptive content associated to novelty) does not mean ascribing creative models or methods a total worth. In fact, scientific models are only valuable to very specific respects (epistemically, socially, ethically), and even to each of these respects, only in very concrete ways. For this reason, philosophers like Parker $(2010,2020)$ argue that to talk about the mere adequacy of a scientific model is rather ambiguous, insofar as the good performance of the model in the past (or regarding certain epistemic aims) does not guarantee its good performance in the future (or regarding other epistemic aims). Instead we should always think in terms of "adequacy-for-purpose" (Parker 2020: 457; see also Poznic 2018; Potochnik 2015; Douglas 2013).

Now, in specific epistemic contexts, what scientists might need the most is to make a research program move forward, break with a cognitively stagnant situation, or escape from an epistemic inertia that blocks the study of possibly fertile paths of investigation. Creativity becomes an important epistemic value precisely in these contexts. Hills and Bird (2018: 17-8) would agree with this claim too, as they accept the importance of creativity in breaking with a tradition that proves to have reached its limits. However, while they think that these situations are very unusual and that creativity is not relevant in the majority of cases, I believe that situations where a tradition has reached its limit might actually require exceptional creativity. Yet, (more moderate) forms of creativity are a desirable value in numerous other scientific situations, such as those described above.

Science needs to be "well-adapted", that is, different epistemic situations require different research strategies, and creative models and methods are particularly desirable when exploration and hot-searches are needed (Currie 2018). The case of the EHT method to study black holes showed this. A less creative method in this case would have been one that for instance focuses on improving individual telescopes, augmenting the angular resolution or sensitivity of each of them. This would have perhaps allowed to make slightly more precise observations of black holes, without the important gaps of information that the EHT method introduces. However, this less creative method wouldn't have been suitable to carry out the bolder exploratory tasks that producing an overall image of a black hole demanded.

Recognizing the plurality of epistemic (and non-epistemic) values and aims, and the possible trade-offs between them, is fundamental to understanding the specific sense in which creative products are valuable. Throughout the paper, I have largely agreed with Hills and Bird (2018: 18) in their criticism to the "unreflective approval of creativity". But, differently to them, I have proposed to amend such fault with more precise, practice-based characterizations of the value of creativity. The suggestions in this section, though, are only a partial attempt to spell out the value of creativity in scientific modelling practices, and do not aim to be sufficient to advance an exhaustive thick account of creativity. 
In order to build such an account, these suggestions would need to be further developed, adjusted, and complemented with other analyses of creative instances in different epistemic, as well as aesthetic and everyday contexts.

\section{Conclusions}

Explaining creativity in a way that is both informative and compatible with our intuitions as speakers embedded in epistemic practices requires to advance thick accounts of creativity. A thick account is one that acknowledges that when we employ the concept of creativity we are expressing both a description and an evaluation. While the description largely entails an element of novelty -and possibly also motivation and imagination when we are considering creativity as a disposition of individuals-, the evaluation entails an element of epistemic worth or merit.

Thus stated, it can seem that a thick account of creativity is equivalent to what the standard view already said, namely, that being creative has two requirements: being novel and being valuable. However, I made an important appreciation. A thick account emphasizes the entanglement between the novelty and the value aspects of creative products, while philosophers who endorse versions of the standard view frequently examine these aspects as separate requirements that are just juxtaposed (Kronfeldner 2014; Kieran 2014). The distinction is important because a mere value requirement is uninformative if not attached to the genuine type of novelty that creative products exhibit.

The key to develop a comprehensive thick account of creativity is to spell out as much as possible what the "novel worth" or "worthy novelty" of creative instances usually comprises in concrete contexts, eventually trying to find commonalities between them. My final proposal consisted in suggesting three possible characterizations of the novel worth of creative instances in scientific practices. I identified the value of creative models and methods (qua creative) with their potential to clarify a tradition, with fruitfulness, and with the fulfilment of exploratory aims. I also stressed the fact that there is a plurality of epistemic and non-epistemic values in scientific practice, usually in trade-off with one another, and that creativity is just one among them, which would be prioritized only in very specific circumstances. This final proposal should be taken as a step forward in the project of advancing a richer and more encompassing thick account of creativity in the future, which would ideally contribute to elucidate the normative role of creative products in other epistemic, aesthetic, and everyday situations.

Acknowledgments I would like to thank the editors of this Topical Collection, Adrian Currie and Anton Killin, as well as two anonymous reviewers, for their very insightful comments on previous versions of this paper. The paper also benefited from feedback at several workshops, including "Exploratory Models and Exploratory Modelling in Science" at TU Berlin (November 2019), "II Workshop Filósofas" at UC3 Madrid (October 2019), "Creativity Across the Arts and Sciences" at Bristol University (April 2019), and "Creativity in Art, Science, and Mind" at Cambridge University (July 2018). The Max Planck Institute for the History of Science has supported this research through a postdoctoral fellowship.

Funding Open Access funding provided by Projekt DEAL. 
Open Access This article is licensed under a Creative Commons Attribution 4.0 International License, which permits use, sharing, adaptation, distribution and reproduction in any medium or format, as long as you give appropriate credit to the original author(s) and the source, provide a link to the Creative Commons licence, and indicate if changes were made. The images or other third party material in this article are included in the article's Creative Commons licence, unless indicated otherwise in a credit line to the material. If material is not included in the article's Creative Commons licence and your intended use is not permitted by statutory regulation or exceeds the permitted use, you will need to obtain permission directly from the copyright holder. To view a copy of this licence, visit http://creativecommons.org/licenses/by/4.0/.

\section{References}

Alexandrova, A. (2017). A philosophy for the science of well-being. New York: Oxford University Press.

Anderson, E. (2004). Uses of value judgments in science: A general argument, with lessons from a case study of feminist research on divorce. Hypatia, 19(1), 1-24.

Axtell, G., \& Carter, J. A. (2008). Just the right thickness: A defense of second-wave virtue epistemology. Philosophical Papers, 37(3), 413-434.

BIAC - OECD (2003). Creativity, Innovation and Economic Growth in the $21^{\text {st }}$ century. An affirmative case for intellectual property rights. https://pdfs.semanticscholar.org/1185/c61825f338c9485de8511b40944 a70344805.pdf. Accessed 15 Oct 2019.

Boden, M. (2004). The creative mind: Myths and mechanisms (2nd ed.). London: Routledge.

Breitenbach, A. (2020). One imagination in experiences of beauty and achievements of understanding. The British Journal of Aesthetics, 60(1), 71-88.

Bronzon, R. (2009). Thick aesthetic concepts. The Journal of Aesthetics and Art Criticism, 67(2), 191-199.

Brown, M. J. (2013). The source and status of values for socially responsible science. Philosophical Studies, 163(1), 67-76.

Burian, R. (1997). Exploratory experimentation and the role of Histochemical techniques in the work of Jean Brachet, 1938-1952. History and Philosophy of the Life Sciences, 19(1), 27-45.

Carroll, N. (2010). Art, creativity, and tradition. In Art in three dimensions (pp. 53-73). Oxford: Oxford University press.

Cropley, D. (2011). The dark side of creativity. In M. Runco \& S. Pritzker (Eds.), Encyclopedia of creativity (pp. 351-357). San Diego: Academic Press.

Cropley, D., et al. (2008). Malevolent creativity: A functional model of creativity in terrorism and crime. Creativity Research Journal, 20(2), 105-115.

Currie, A. (2018). Existential risk, creativity \& well-adapted science. Studies in History and Philosophy of Science., 76, 39-48. https://doi.org/10.1016/j.shpsa.2018.09.008.

Dancy, J. (1995). In defense of thick concepts. Midwest Studies in Philosophy, 20, 263-279.

Douglas, H. (2013). The value of cognitive values. Philosophy of Science, 80(5), 796-806.

Elgin, C. (2008). Trustworthiness. Philosophical Papers, 37(3), 371-387.

Elgin, C. (2017). True enough. Cambridge: MIT Press.

Elliott, K. (2007). Varieties of exploratory experimentation in Nanotoxicology. History and Philosophy of the Life Sciences, 29(3), 313-336.

European Commission. Regulation (EU) No 1295/2013 of the European Parliament and of the Council of 11 December 2013 establishing the Creative Europe Programme (2014 to 2020). https://eur-lex.europa. eu/legal-content/EN/TXT/HTML/?uri=CELEX:32013R1295\&from=EN. Accessed 15 Oct 2019.

Fara, P. (2002). Newton: The making of a genius. London: Macmillan.

Fisher, R. A. (1930). The genetical theory of natural selection. Oxford: The Clarendon Press.

Fricker, M. (2007). Epistemic injustice: Power and the ethics of knowing. Oxford: Oxford University Press.

Frigg, R., \& Nguyen, J. (2017). The turn of the valve: Representing with material models. European Journal for the Philosophy of Science, 8(2), 205-224.

Galluzi. (2020). The Italian renaissance of machines. Cambridge: Harvard University Press.

Gaut, B. (2003). Creativity and imagination. In B. Gaut \& P. Livingston (Eds.), The creation of art (Ch. 6, pp.148-73). Cambridge: Cambridge University Press.

Gaut, B. (2010). The philosophy of creativity. Philosophy Compass, 5(12), 1034-1046.

Gaut, B. (2012). Creativity and rationality. The Journal of Aesthetics and Art Criticism, 70(3), 259-270. 
Gaut, B. (2018). The value of creativity. In B. Gaut \& M. Kieran (Eds.), Creativity and philosophy (pp. 124 139). London: Routledge.

Gelfert, A. (2018). Models in search of targets: Exploratory Modelling and the case of Turing patterns. In A. Christian, D. Hommen, N. Retzlaff, \& G. Schurz (Eds.), Philosophy of science. European studies in philosophy of science (pp. 245-269). Cham: Springer.

Hills, A., \& Bird, A. (2018). Against creativity. Philosophy and Phenomenological Research, 99, 694-713. https://doi.org/10.1111/phpr.12511.

Ivani, S. (2019). What we (should) talk about when we talk about fruitfulness. European Journal for Philosophy of Science, 9, 4.

James, K., \& Taylor, A. (2010). Positive creativity and negative creativity (and unintended consequences). In D. H. Cropley, A. J. Cropley, J. C. Kaufman, \& M. A. Runco (Eds.), The dark side of creativity (pp. 3356). New York: Cambridge University Press.

Kant, I. (1790/2001). Critique of the Power of Judgment. Edited and translated by Matthew, E. and Guyer, P. New York: Cambridge University press.

Kemp, M. (2006). Leonardo da Vinci. The Marvellous works of nature and man. Oxford: Oxford University Press.

Kieran, M. (2014). Creativity as a virtue of character. In S. Kauffman (Ed.), Paul, E. Oxford: Oxford University Press: The Philosophy of Creativity.

Kirchin, S. (2013). Thick concepts. Oxford: Oxford University Press.

Klausen, S. (2010). The notion of creativity revisited: A philosophical perspective on creativity research. Creativity Research Journal, 22(4), 347-360.

Kotzee, B., \& Wanderer, J. (2008). Introduction: A thicker epistemology? Philosophical Papers, 37(3), 337343.

Kronfeldner, M. (2014). Creativity naturalized. The Philosophical Quarterly, 59(237), 577-592.

Kuhn, T. (1977). Objectivity, value judgment, and theory choice. In Essential tension (pp. 320-339). Chicago: Chicago University Press.

Kyle, B. (2013). How are thick terms evaluative? Philosophers Imprint, 13(1), 1-20.

Kyle, B. (2016). Thick concepts. Internet Encyclopedia of Philosophy. https://www.iep.utm.edu/thick-co/.

McDowell, J. (1998). Mind, value, and reality. Boston: Harvard University Press.

McLaren, R. (1993). The dark side of creativity. Creativity Research Journal, 6(1-2), 137-144.

McLeod, M., \& Nersessian, N. (2013). The creative industry of integrative systems biology. Mind Soc, 12, $35-48$.

McMullin, E. (1976). The fertility of theory and the unit for appraisal in science. In R. Cohen et al. (Eds.), Essays in memory of Imre Lakatos (pp. 395-432). Dordrecht: Springer Netherlands.

McMullin, E. (1979). The ambiguity of historicism. In P. Asquith \& H. Kyburg (Eds.), Current research in philosophy of science (pp. 55-83). Philosophy of Science Association: Lansing.

Miller, A. (1998). The gift of creativity. Roeper Review, 21(1), 51-54.

Morgan, M. (2012). The world in the model: How economists work and think. Cambridge: Cambridge University Press.

Nolan, D. (1999). Is fertility virtuous in its own right? The British Journal for the Philosophy of Science, 50(2), 265-282.

Novitz, D. (2003). Explanations of creativity. In B. Gaut \& P. Livingston (Eds.), The creation of art: New essays in philosophical aesthetics (pp. 174-191). Cambridge: Cambridge UP.

Nyrup, R. (2018). Of water drops and atomic nuclei: Analogies and pursuit worthiness in science. The British Journal for the Philosophy of Science., 71, 881-903. https://doi.org/10.1093/bjps/axy036.

Parker, W. (2010). Scientific models and adequacy-for-purpose. Modern Schoolman, 87(3-4), 285-293.

Parker, W. (2020). Model evaluation: An adequate-for-purpose view. Philosophy of Science, 87, 457-477.

Paul, E., \& Kauffman, S. (Eds.). (2014). The philosophy of creativity. Oxford: Oxford University Press.

Paulus, P., \& Coskun, H. (2011). Group creativity. In M. Runco \& S. Pritzker (Eds.), Encyclopedia of creativity (pp. 575-580). San Diego: Academic Press.

Potochnik, A. (2015). The diverse aims of science. Studies in History and Philosophy of Science, 53, 71-80.

Potochnik, A. (2017). Idealization and the aims of science. Chicago: Chicago University Press.

Poznic, M. (2018). Thin versus thick accounts of scientific representation. Synthese, 195, 3433-3451.

Putnam, H. (2002). The collapse of the fact/value dichotomy. Boston: Harvard University Press.

Roberts, D. (2013). Thick concepts. Philosophy Compass, 8(8), 677-688.

Roberts, D. (2018). Thick epistemic concepts. In C. McHugh, J. Way, \& D. Whiting (Eds.) Metaepistemology (pp. 159-178). Oxford: Oxford University press.

Schaffer, S. (1994). Making up discovery. In Boden: M. Dimensions of Creativity. MIT Press.

Šešelja, D., \& Straßer, C. (2013). Kuhn and the question of pursuit worthiness. Topoi, 32, 9-19. 
Siegel, H. (2008). Is 'education' a thick epistemic concept? Philosophical Papers, 37(3), 455-469.

Steinle, F. (1997). Entering new fields: Exploratory uses of experimentation. Philosophy of Science (Proceedings), 64, 65-74.

Sternberg, R. and Lubart, T. (1999). The concept of creativity: Prospects and paradigms. In R. Sternberg (Ed.), Handbook of creativity (pp. 3-15). Cambridge: Cambridge University press.

Stokes, D. (2008). A metaphysics of creativity. In K. Thomson-Jones (Ed.), Stock, K (pp. 105-124). PalgraveMacmillan: New Waves in Aesthetics.

Stokes, D., \& Paul, E. (2016). Naturalistic approaches to creativity. In J. Systma \& J. Buckwalter (Eds.), The Blackwell companion to experimental philosophy. Oxford: Blackwell.

The Event Horizon Telescope Collaboration et al. (2019). The Astrophysical Journal Letters, 875: L1, L2, L3, L4, L5 and L6.

Turner, D. (2019). Paleoaesthetics and the practice of paleontology. Cambridge: Cambridge University Press.

UNESCO (2017). Resolution 71/284, World Creativity and Innovation Day, UN general assembly. https://undocs.org/A/RES/71/284. Accessed 15 Oct 2019.

Väyrynen, P. (2013). Thick concepts and Underdetermination. In S. Kirchin (Ed.), Thick concepts. Oxford University Press.

Vines, D. (2000). The Phillips machine as a 'progressive' model. In R. Leesona (Ed.), W. H. Phillips: collected works in contemporary perspective (pp. 39-67). Cambridge: Cambridge University press.

Weisberg, R. (1986). Creativity: Genius and other myths. New York: W.H. Freeman.

Williams, B. (1985). Ethics and the limits of philosophy. Boston: Harvard University Press.

Zangwill, N. (2001). Metaphysics of beauty. Ithaca: Cornell University Press.

Publisher's note Springer Nature remains neutral with regard to jurisdictional claims in published maps and institutional affiliations. 